\title{
OCORRÊNCIAS DE FORAMINÍFEROS FÓSSEIS NO BRASIL
}

\author{
Por \\ SETEMBRINO PETRI (*) \\ (Com 4 Estampas).
}

SUMMARY Brazil.

By the first time are described some fossil Foraminifera from

The article begins with a short sketch of the previous report on findings of fossil Foraminifera in Brazil.

Foraminifera coming from Caraparú. State of Pará, probably referrible to the Firabas formation (Miocene) are discussed; however no systematic determinations were reached.

Upper Paleozoic Foraminifera found at the Parauari River (Itaituba formation) State of Amazonas, are described and some generic entities recognized (Endothyra, Plectogyra) Cretaceous Foraminifera from two different locaiities are also considered (Gramane River, State of Paraiba do Norte; Fonta dos Barcos, State of Sergipe)

The author gives longer considerations on the fossils collected at Ponta de Pirabas (Pirabas formation) of Miocene age, describing:

Quinqueloculina sp. a, Q. sp. b., Q. sp. c, Pyrgo sp. a, P. sp. b., Peneroplis sp., Discorbis? sp.., "Rotalia" sp., Gyroidina? sp., Eponides sp., Nonion sp. a, $N$ sp. b.

\section{RESUMO}

Sāo descritos pela primeira vez alguns foraminiferos fósseis do Brasil.

O artigo inicia com um breve apanhado das informações prévias sobre ocorrências de foraminiferos fósseis do Brasil.

(*) Antigo Assistente do Del. (icologia or P'aleontolosia da Far. Filosofia. Cîncias e latras, Inis. São I’aulo, atualmente trabalhando no Conselho Nacional do Petroleo. 
Discute-se material com foraminiferos procedente de Caraparú, Estado do Pará, provavelmente referivel à formaçāo Pirabas de idade miocenica. Nāo foram atingidas, porém, determinações sistemáticas.

Segue-se a descriçāo de alguns foraminiferos do Paleozoico Superior, procedentes do Rio Parauarí (formaçāo Itaituba). dentre os quais foram genericamente reconhecidos Endothyra e Plectogyra. Séo considerados, entāo, foraminiferos cretacicos vindos do Rio Gramane, Estado de Paraiba do Norte e Ponta dos Barcos, Estado de Sergipe.

Detem-se o autor mais demoradamente sobre fósseis coletados na Ponta de Pirabas (formaçāo Pirabas), cuja idade é considerada miocenica. Descreve:

Quinqueloculina sp. a, Q. sp. b., Q. sp. c, Pyrgo sp. a, P. sp. b., Peneroplis sp., Discorbis? sp.., "Rotalia" sp., Gyroidina? sp., Eponides sp., Nonion sp. a, N. sp. b.

\section{A) - INTRODUÇão}

A presente nota nāo pretende senāo divulgar algumas ocorrências de foraminiferos fósseis no norte e nordeste brasileiro. O visu principal nāo foi o da sistemática que é fornecida contudo para o caso dos foraminiferos fósseis da formaçāo Pirabas, formaçāo esta de idade miocênica segundo Maury (8, p. 3). ocorrente na costa nordeste do Estado do Pará. Chequei, porém, só à determinaçāo ǵenérica destes fósseis em virtude da escassês de espécimes.

A titulo de informaçāo sôbre o pouco que se conhece dos foraminiferos fósseis do Brasil, segue-se um resumo das referências a respeito.

Emmanuel Liais ( 7 p. 147) colheu corpos lenticulares de 2 a $3 \mathrm{~mm}$. de diâmetro, lembrando foraminiferos, em calcário pertencente à série Bambuí (Siluriano?). próxima a Pitangui e Abadia, Minas Gerais. Derby (3, p. 483), cita em calcário pertencente à série Itaituba, Carbonifero, Fusulina sp., proveniente da localidade de Itaituba, Estado do Pará. Maury (9, p. 283) cita um espécime discoide, quebrado em dois, dando uma secçāo transversal sugestiva de um foraminifero. proveniente da série Sergipe, Cretáceo do Estado de Sergipe. Remetida a amostra ao dr. Cushman, êste declarou ser o espécime semelhante a uma secçāo de Discocyclina, porém nāo poude identificar com certeza. Segundo Oliveira e Leonardos $(10$, p. 531). Branner cita numerosos foraminíferos em certas camadas pertencentes à série Araripe, Cretáceo, que afloram nos limites entre o Ceará, Pernambuco e Piauí. Também na série Grajaú, Cretáceo de Maranhāo e Piaui, Antonio Dias teria encontrado foraminiferos, segundo os mesmos autores (Idem, p. 535). Segundo Glycon de Paiva (11, p. 57) foram verificados forami- 
niferos em lâminas de calcário proveniente da ilha de Itamaracá, Estado de Pernambuco. Estas lâminas foram preparadas por Paulo Erichsen de Oliveira. Ao que parece, êsse calcário deve ser incluido na formaçāo Maria Farinha, colocada duvidosamente no Cretáceo, podendo ser contudo paleocênica ou eocênica.

É interessante lembrar que Maynard P White (12, p. 55). cita um trabalho de Bonnermann, publicado em 1855, no Erman's Archiv Wiss. Kunde, vol. 14, no qual êste último autor descreve às páginas 153-154, uma nova espécie de foraminifero, Daucina ermaniana, cujo genótipo provém do Terciário de Corcovado, próximo ao Rio de Janeiro. Obviamente houve um engano, pois é sabido que nāo ocorre Terciário nessa localidade.

Tanto quanto pude verificar, sāo estas as únicas noticias a respeito de foraminíferos fósseis brasileiros, constando todas de simpies citações desacompanhadas de ilustraçāo ou de descriçāo.

\section{B) - CALCáRIO de CARAparú - belèM}

Examinando lâminas obtidas de amostras de calcário provenientes do igarapé Caraparú, próximo a Belém, Estado do Pará, coletadas pelos Frofs. Joāo Dias da Silveira e Antonio da Rocha Penteado $\left({ }^{*}\right)$ durante uma excursāo organizada pelo Conselho Nacional de Geografia, tive oportunidade de notar testas $\left({ }^{* *}\right)$ de foraminíferos.

\section{Situação geogrãfica (Fig. 1)}

Segundo informou-me o Frof. Penteado, a exposiçāo do calcário em consideraçāo situa-se a cêrca de trinta quilômetros a leste de Belém. Estado do Pará, no baixo curso do igarapé Caraparú e 800 a 1.000 metros à montante de sua fóz no rio Guamá. formando ai uma corredeira, elevando-se a rocha, aproximadamente, a einqüenta centimetros acima do nível das águas na maré baixa. Na maré alta, o igarapé cobre o afloramento, fazendo-o desaparecer. tornando o referido curso d'água navegável. Êste afloramento corta transversalmente o igarapé. possuindo cêrca de dezoito metros de extensāo, que corresponde à largura do igarapé na maré baixa.

(*) - Deixo aqui os meus agradecinentos aos professores acima mencionados, que não sú ofereceram as amostras de calcário de Carapará a Departamento de Geologia "I'aleontologia da Faculdade de Filosofia, Ciências e Letras da Iniversidade de São l'aulo, permitindo que as neesmas fossem estudadas, como também forneceram minuciosas informaçóes sôbre o citado afloramento.

(**) - E aqui usada a palarra testa em lugar de concha, a qual i secretada por orgãos especiais como no caso dos moluscos. 
Convém salientar a localizaçāo geográfica dêsse afloramento em uma área tida até agora como de franca sedimentaç⿳亠丷厂̆ quaternária.

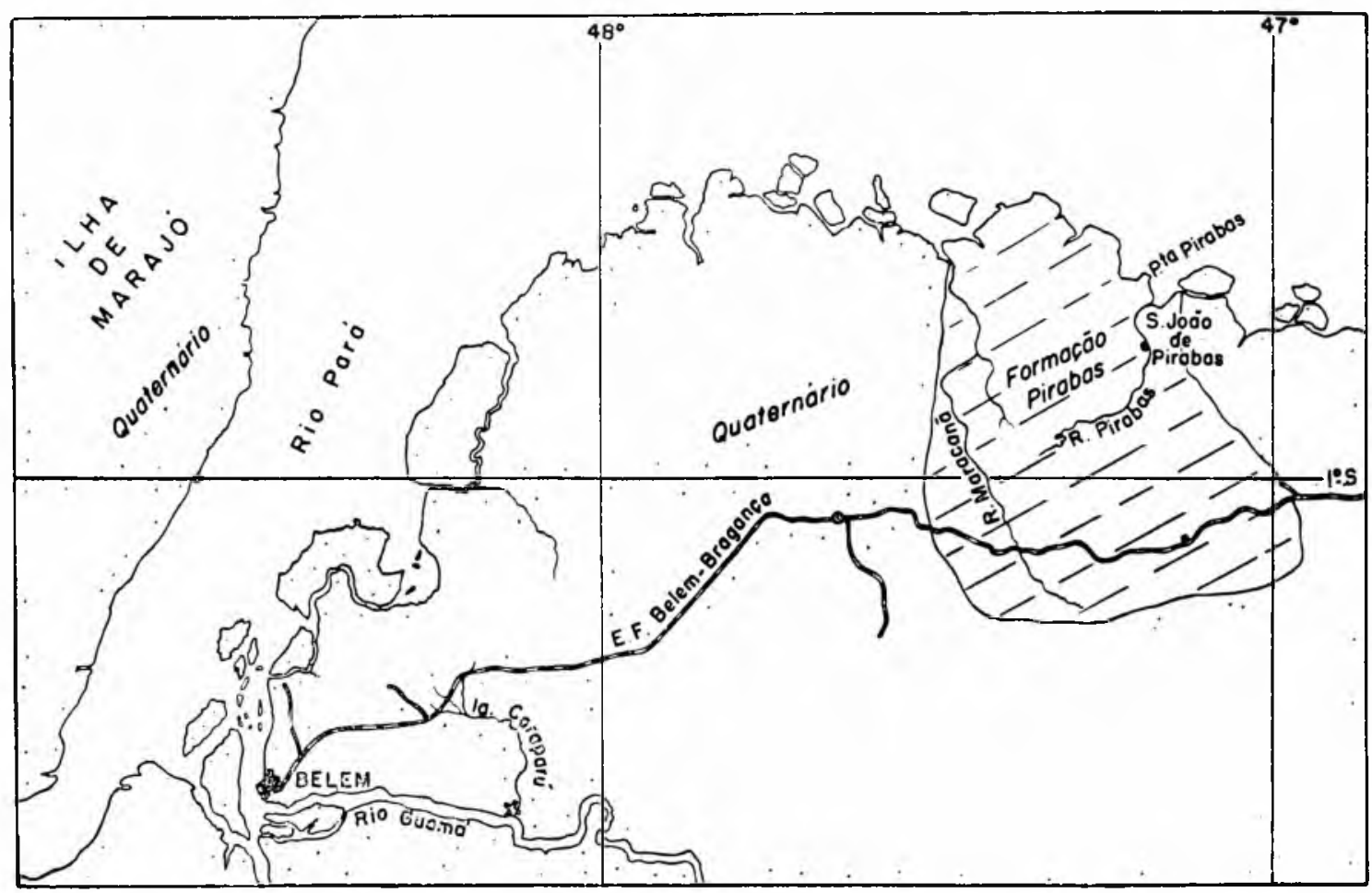

Fig. 1 - Mápa de parte do Estado do Pará, mostrando as relarnes entre a área de ocorrência da formação Pirabas e o afloramento de calcúrio do Tgaraps Caraparú, marcado com o sinal $x$. De acordo com mapa geolígico de $\lambda$. Oliveira, in traducio de Katzer, $1933(6)$.

\section{Caractéres da rocha matriz}

Macroscópico: - Calcário brechoide composto de fragmentos centimétricos de calcário original, atravessados por vênulas irregulares de calcita. Os fragmentos sāo cripto-cristalinos, compáctos, de côr ligeiramente creme, contendo impressões que aparentam pedaços de conchas. As vênulas de calcita sāo de côr branca, granulaçāo milimétrica, possuindo frequentemente cavidades com revestimento de cristais de calcita.

Microscópico: - No microscópio observa-se a mesma natureza brechoide, com recristalizaçāo irregular de calcita. Nos fragmentos compactos de calcário original encontram-se raros foraminiferos, geralmente um foraminífero por centimetro quailrado de secção delgada, e restos que lembram fragmentos de conchas. O calcário mostra silicificaçāo incipiente, com precipitaçāo de calcedônia, principalmente nas vênulas. 
Na opiniē̄o do Dr. Viktor Leinz $\left({ }^{*}\right)$ que examinou a rocha, apesar do aspecto cristalino da matriz, a conservaçāo dos fósseis e as cavidades ras vênulas indicam que nāo se deu nenhum metamorfismo térmico, mas apenas cataclase que fragmentou o calcário, a qual foi acompanhada por recristalização parcial do mesmo, indicando portanto a açāo de movimentos tectônicos.

Col. II/46, Departamento de Geologia e Paleontologia Fac. Filos. Ciênc. Letras, Univ. S. Paulo.

\section{Foraminiferos}

A presença de foraminiferos no calcário do igarapé Caraparú é só verificada em lâminas delgadas, pois nāo foi possivel, por enquanto, o isolamento dos mesmos. O estado de conservaçāo dêstes fósseis nāo é dos mais satisfatórios.

Distinquem-se nes lâminas, pelo menos três fórmas multiloculares: 1) Unisserial, retilinear, cada câmara sendo aproximadamente cilindrica (Foto n. 1). 2) Bisserial, retilinear, 3) Trocospiralada, deprimida.

Das fórmas de testa unisserial, retilinear, o individuo maior possue cêrca de $0.45 \mathrm{~mm}$. de comprimento. A câmara maior mede $0.21 \mathrm{~mm}$. por $0.075 \mathrm{~mm}$. Das fórmas bisseriais retilineares, o maior individuo possue $0,28 \mathrm{~mm}$. por $0,15 \mathrm{~mm}$. A câmara maior tem as dimensões de $075 \mathrm{~mm}$. por $0.06 \mathrm{~mm}$. Das fórmas de testa trocospiraiada, o maior indivíduo possue os diâmetros de $0.36 \mathrm{~mm}$. e $0,27 \mathrm{~mm}$. A câmæra maior mede $0.13 \mathrm{~mm}$. por $0,12 \mathrm{~mm}$. Convém salientar que estas medidas sāo aproximadas visto que foram medidas secções de fósseis e nāo individuos isolados. O grau de conservaçāo dêsses fósseis nāo permite a verificaçāo se a parede era de natureza calcária ou arenosa.

Col. II/47-49 D.G.P

\section{Correlação geológịca}

É possivel que o calcário aqui examinado pertença à formaçāo Pirabas, cuja área tipo ocorre na costa nordeste do Estado do Pará. Esta formaçāo, segundo Maury (8, p. 3). é de idade miocênica inferior. Lembro que os afloramentos de calcário mais próximos da rocha do igarapé Caraparú pertencem à formąçāo Pira-

(*) - O autor arradece a gentileza do Dr. Viktor lecinz qur nío sóm se prontificou a examinar petrogmificamente a rocha, como, timbim, apresentou valiosas sugestoes que muito contriburam para a billoria da fomma de apresentação lesta nota. 
bas. Contudo o calcário de Caraparú é compacto e recristalizado, contrastando com o calcário tipico da formaçāo Pirabas, que é poroso, pardacento, composto de conchas, muitas das quais quebradas e recristalizadas posteriormente, cimentadas com cimento escasso. Além disso o calcário de Pirabas é densamente fossilifero enquanto nas amostras aqui estudadas os únicos fósseis encontrados foram raros foraminiferos e fragmentos de concha calcária.

O calcário do igarapé Caraparú representaria, de acordo com os conhecimentos atuais, o extremo sudoeste da formaçāo Pirabas. Êsse afloramento do igarapé Caraparú viria ampliar grandemente a área conhecida da formaçāo Firabas, caso éle pertença realmente à essa formaçāo, conforme póde-se vêr no mapa da fig. 1, onde está representada, de acordo com Katzer (6, mapa anexo), a área de ocorrência da formaçāo Pirabas, segundo Paulino F de Carvalho e outros.

\section{C) - OUTRAS OCORRÊNCIAS DE FORAMINÍFEROS FóSSEIS}

Sāo citadas abaixo em ordem ascendente na escala cronológica, outras localidades onde foraminiferos fósseis foram verificados pelo autor.

1) Calcário carbonifero da série Itaituba, proveniente do rio Parauari, Estado do Amazonas. Os foraminíferos se mostram muito abundantes. Em certas lâminas a sua frequência atinge no minimo 10 individuos por centimetro quadrado. Verifiquei os seguintes tipos de testas multiloculares:

a) Unisserial, retilinear, com câmaras aumentando gradualmente.

Nesta fórma a parede é espessa e diferenciada em duas partes, sendo que a interna é mais transparente, exatamente como acontece com a parede de certos gêneros arenosos, tais como Deckerella. Essas testas parecem ser unisseriais, contudo nāo se pode afirmar com certeza se as câmaras iniciais sāo unisseriais.

b) Planospiral, dotada de muitas câmaras, as quais nāo se projetam alem da sutura espiral, involuta.

c) Fórma com câmaras esféricas, as quais se projetam alem da sutura espiral, involuta. 


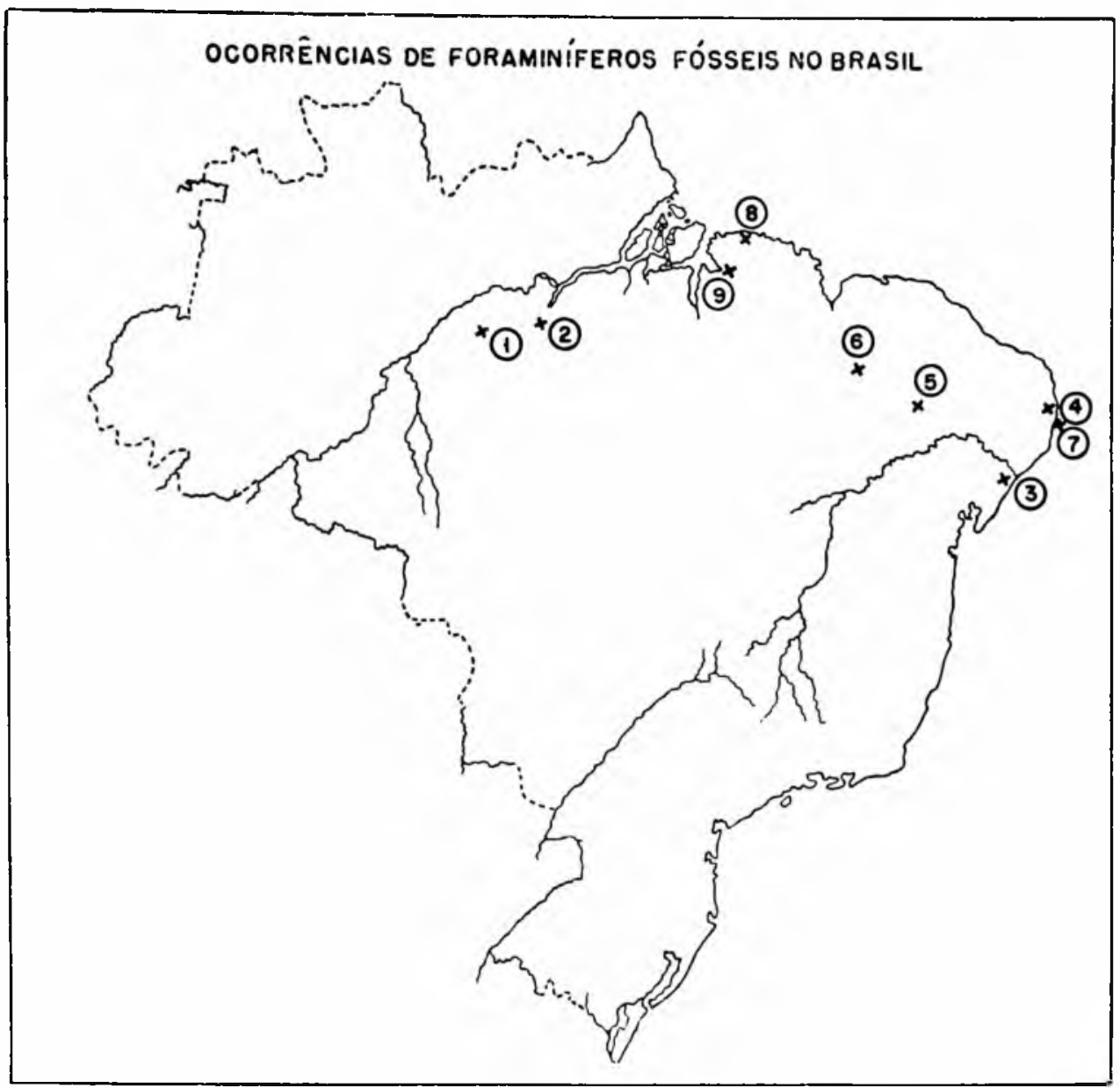

Fig. 2 - Legenda:

Carbonifero Série Itaituba

Cretáceo?

Sërie Sergipe Grupo Paraiba

Sirie Araripe

Série Grajaú
1 - Rio I'arauari, Fst. Anazonas.

2 - Itaituba, list. Pará. (Citado por Derby).

3 - Porto dos Barcos, Est. Sergipe.

4 - Fazenda Congo, vale do rio Gramame, Jist. Paraiba.

5 - Chapada do Araripe, limites entre Cearí, I'ernambuco e Piaui. (Citado por Branner).

6 - Afloramento nāo precisado entre Maranhão é l’iıui. (Citado por A. Dias).

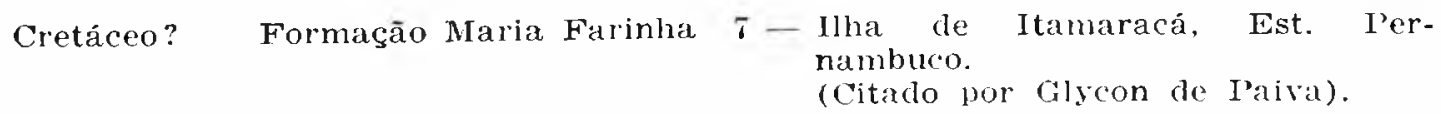




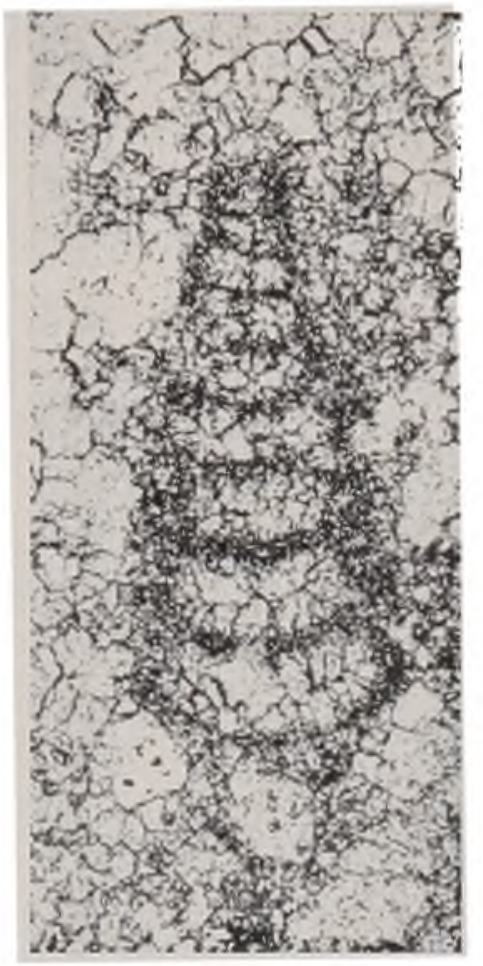

Foto n. 1 - Foraminifero proveniente do Igarapé Caraparú, visto em lamins. delgada. × 115.

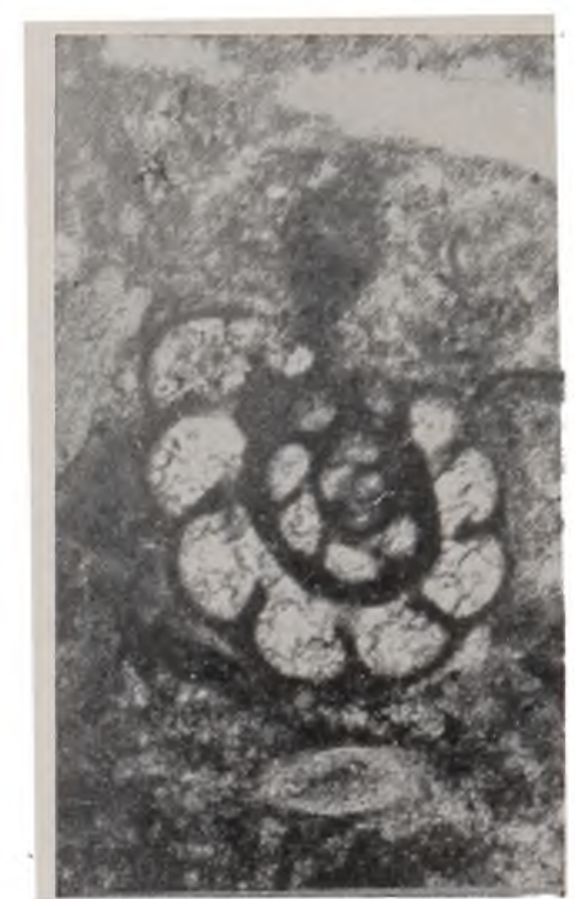

Foto n. 2-- Plectoryra sp. procedente do rio Parauari. visto em lamina delgada.

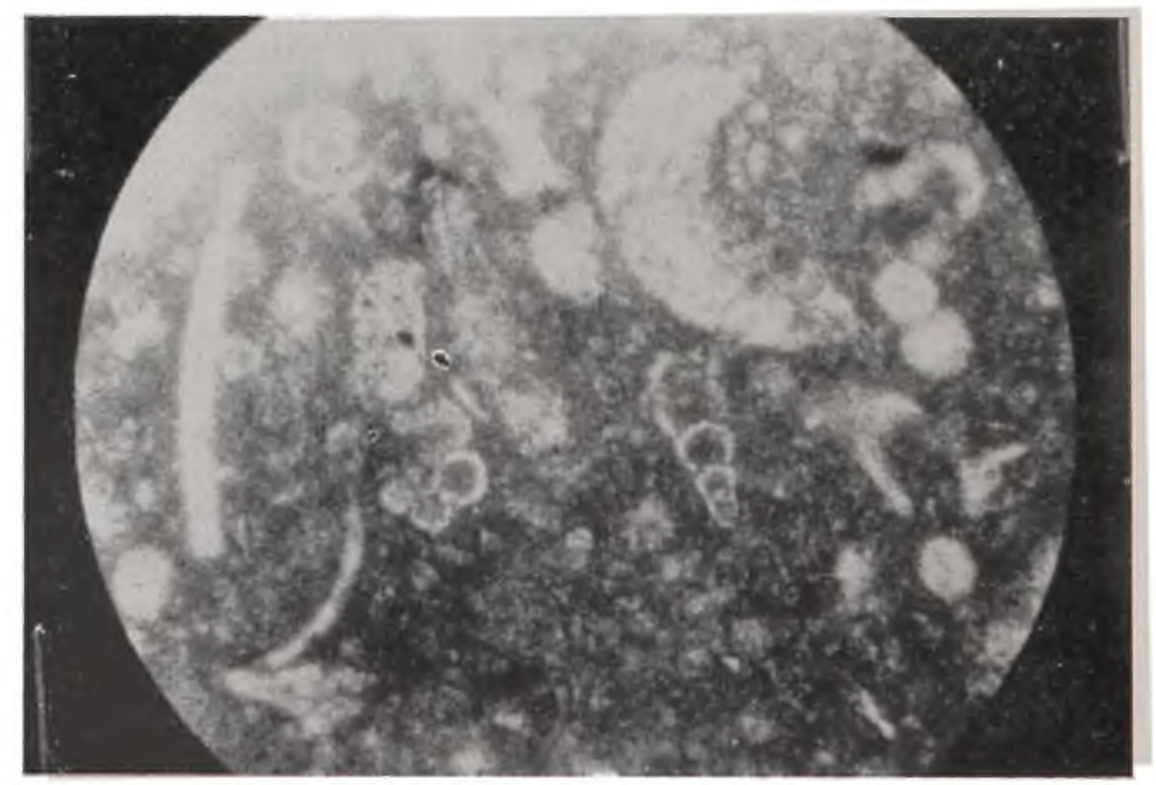

Foto n. 3 - Foreminiferos procecientes da Fazenda Congo, vicle do rio Gimmine, Puriaba do Norte, vistos en lamina delgada. $\times \quad 5 \bar{i}, 5$. 
O foto n. 2 mostra uma secçāo transversal de um individuo pertencente a fórma aqui considerada. Esta secçāo é excepcionalmerte bem orientada. O caráter da parede, o tipo de enrolamento irregular das primeiras voltas do corpo, o número relativamente numeroso das câmaras, a fórma esférica destas e os septos curtos os quais nāo formam um limite distinto com a sutura espiral, indicam ser esta fórma referivel ao gênero Endothyra, tal como é compreendido por Cushman (1, p. 102) e por Glaessner (5, p. 107). Pelo caráter da parede com granulaçāo fina e escura em iuz transmitida, aliar-se-ia a E. bowmani Brown, de acordo com a classificaçāo de Rauser (Citado por Glaessner, idem, idem). Contudo E. bowmani Brown é uma fórma planospiral enquanto na fórma aqui considerada, o enrolamento da testa se dá em três planos, de maneira que estamos aqui deante de um representante do gênero Plectogyra, creado por Zelier (13, p. 3) Zeller estudou o desenvolvimerto estraticráfico dos foraminiferos endothyroides (Endothyı B Brown e Fiectogyra Zeller) dos Estados Unidos da América do Norte, em rochas que se distribuem do Devoniano Superior ao Fennsylvaniano. A Flectogyra da série Itaituba possue forte depósito secundário cobrindo o assoalho das câmaras, especialmente da última volta do corpo. Êsse depósito é homogêneo, e por êsse cajáter e pela pujança dêsse depósito secundário, a fórma aqui considerada poderia ser comparada com os representantes do gênero, mais altos estratigràficamente, estudados por Zeller, isto é, com os representintes pensilvanianos, pois Zeller nāo estuda fósseis permianos. Contudo a atitude dos septos, dirigidos para a frente, formando um ângulo agudo com a sutura espiral, o número menor de septos os auais sāo reforçados na parte livre, logo acima co trinel por ćepósitos secundários e a presença de sinais de reabsorçío do depósito secundário do assoalho das câmaras, evidenciado por um maior desenvolvimento dêste depósito na parte anterior próxima a abertura, sāo caractéres primitivos segundo aquele autor. Nāo se pode contudo extrapolar os dados de Zeller, obtidos em uma regiāo restrita para o caso do Carbonifero do norte do Brasil. Necessitam-se estudos da evoluçāo dos foraminiferos endothyroides em outras partes do mundo para se obter entāo dados mais seguros.

d) Fórma trocospiralada, com poucas câmaras, as quais aumentam ràpidamente.

Existem ainda outras fórmas mais complexas de foraminiferos. cujo tipo de arranjo das câmaras irá depender de estudos mais minuciosos.

Col. II/50-52 D.G.P

2) Calcário cretáceo do grupo Paraiba, proveniente da fazenda Congo, vále do rio Gramame. Estado da Paraiba. Aqui os foraminiferos sāo relativamente abundantes, cêrca de quatro a cinco individuos por centimetro quadrado em certas lâminas, e às vezes 
até mais (Foto n. ) Distinguem-se fórmas enroladas e retilineares. Todos os foraminiferos aqui verificados sầo muito pequenos em relaçāo aos provenientes de outras localidades estudadas. Compare-se por exemplo os fotos n. ${ }^{05} 1$ e 3. (A ampliaçāo do foto n. 1 é duas vezes a do foto $n$. 3). Dentre os foraminíferos do Cretáceo da Paraiba, sāo muito comuns fórmas enroladas cujas câmaras sāo esféricas, bojudas, projetando-se muito alem da sutura espiral. Nas secções delgadas, algumas dessas fórmas mostram as câmaras esféricas cobertas de pequenos espinhos. Talvez elas possam ser referidas às globigerinidae. Predominam portanto no calcário em consideraçāo, fórmas planctônicas. As lâminas dêsse calcário lembram, pela abundância de foraminiferos planctônicos, fotografias de secções delgadas de margas foraminiféricas do Cretáceo e do Paleoceno, publicadas por Glaessner (5, Est. 13 e 14).

Col. II 53-54 D.G.P.

3) Calcário cretáceo da série Sergipe, proveniente de Porto dos Barcos. Estado de Sergipe. Os foraminíferos sāo pouco nunerosos, cêrca de um indivíduo por centímetro quadrado nas amostras examinadas e em estado de conservaçāo pouco satisfatório.

Col. II/55 D.G.P

4) Calcário miocênico da formaçāo Pirabas, proveniente de Ponta de Pirabas, Estado do Pará.

Sòmente foi conseguido o isolamento de foraminiferos fragmentando o calcário de Ponta de Pirabas em pedaços pequenos e fervendo-os em uma soluçāo de sulfato de sódio e deixando depois o sulfato cristalizar por evaporaçăo do dissolvente. O sulfato em soluçāo penetra nas fendas e poros da rocha e, pela força de cristalizaçāo desagrega-a. A operaçāo pode ser repetida diversas vezes. O calcário de Pirabas presta-se muito bem à técnica pelo fato de ser poroso. Êstes fósseis sāo descritos abaixo.

\section{D) - DESCRIÇĀO DOS FORAMINIFEROS FÓSSEIS DA FORMAÇÃO PIRABAS}

OS foraminíferos estudados provém de afloramentos de calcário de Fonta de Pirabas (V Fig. 1). O calcário é pardacento e contém fragmentos de conchas recristalizados posteriormente, cimentados com cimento escasso. É densamente fossilifero sendo a fauna rica e variada, predominando entretanto, nas amostras examinadas pelo autor, pelecipodos. Êstes moluscos estāo em sua maioria conservados sob a fórma de moldes externos e internos.

Maury (8, p. 14) e Gonzaga de Campos (em Maury, Idem, p. 670) admitem águas rasas, próximas à costa como ambiente de deposiçāo do calcário Pirabas, baseando esta afirmativa na presença de espécies de moluscos associadas com equinodermes e restos de vertebrados terrestres.

Das fórmas de foraminiferos estudadas abaixo, as mais comuns sāo Quinqueloculina, Pyrgo e Nonion. O material provém 
conjunto, como cada uma de suas câmaras. Como na espécie acima, a abertura abre-se diretamente na superfície da concha, sem ser prolongada em pescoço e é grande, tendo como dente sòmente uma pequena protuberância, quasi imperceptivel.

Dimensões: comprimento $0,39 \mathrm{~mm}$; largura $0,36 \mathrm{~mm}$.

Col. II/57 D.G.P.

\section{Quinqueloculina sp. c}

Est. 1. fig. 7.9.

Testa muito alongada com comprimento cêrca de duas vezes e meia a largura, com periferia arredondada e suturas deprimidas. Câmaras arredondadas, estreitas e alongadas, ligeiramente curvas. Parede lisa, brilhante, calcária. Abertura pequena, projetada em um pescoço alongado. Nāo foi possível a verificaçāo da existência ou nāo de um dente.

Dimensões: comprimento $0,62 \mathrm{~mm}$; largura $0,24 \mathrm{~mm}$.

A presente fórma pertence à secçāo do gênero Quinqueloculina estabelecida por Deshayes (em Ellis e Messina, Catalogue of Foraminifera, Quinqueloculina D'Orbigny emend. Deshayes, 1832) caracterisada por espécies muito alongadas, geralmente com a abertura prolongada em um pescoço.

Col. II $/ 58$ D.G.P.

\section{Pyrgo sp. a}

Est. I, fig. 10; Est. II, fig. 1-3.

Testa rotunda, ligeiramente mais longa que larga, um tanto mais larga que espêssa. Cûmaras arredondadas, periferia arredondada. Suturas distintas, deprimidas, formando uma linha sinuosa em ambas as extremidades. Na extremidade anterior (da abertura) a linha sinuosa é disposta de tal maneira que olhando-se do centro para a periferia, as partes côncavas sāo voltadas para a câmara mais jovem. Na extremidade posterior a linha sinuosa é disposta de tạl maneira que as partes côncavas sāo voltadas para a câmara precedente. Na extremidade oposta à abertura, há uma ligeira excavaçāo em ambos os lados da câmara precedente. Parede lisa e polida. Abertura oval com um pequeno dente truncado. Nos fósseis aquí estudados nāo é claro se êsse dente se bifurcava ou nāo. O exterior é formado por duas câmaras dispostas em oposiçāo, uma à outra. A verificaçāo do arranjo típico do gênero foi possivel por intermédio de secções de indivíduos. (Est. 1, fig. 10)

Dimensões: comprimento $0,66 \mathrm{~mm}$; largura $0,54 \mathrm{~mm}$; espessura $0.43 \mathrm{~mm}$.

As proporçōes e a fórma geral da testa, e o desenho sinuoso da sutura em ambas as extremidades da testa lembram a espécie Pyrgo subsphaerica (D'Orbigny), de acôrdo com a ilustraçāo for- 
de Ponta de Pirabas, mas nāo está especificado contudo se pertence à um estrato ou a diversos estratos. Em vista disso, a fauna descrita abaixo nāo póde ser considerada como representando uma fîunula no sentido paleontológico.

Além dos gêneros referidos abaixo, outras fórmas por ora indeterminadas foram ainda verificadas pelo autor, provenientes ainda de Ponta de Pirabas.

A ordem adotada de apresentaçāo das familias e gêneros foi a seguida por Cushman em seu tratado sôbre foraminiferos.

\title{
Familia Miliolidae \\ Quinqueloculina sp. a
}

Est. I, fig. 1-3.

Testa pequena, com comprimento aproximadamente uma vez e meia a largura, com periferia arredondada. Suturas distintas, um tanto profundas. Câmaras arredondadas, distintas, projetando-se um pouco. A parede é calcária, sem ornamentaçāo e apresenta em tôdas as fórmas examinadas, uma côr marron amarelada. Abertura grande, semilunar, aparecendo diretamente na superfície sem ser prolongada em um pescoço, e dotada de um dente curto e achatado, um tanto largo, com extremidade truncada.

Foram medidos o comprimento e a largura, mostrando em diversos individuos, uma variaçāo no comprimento, de $0,24 \mathrm{~mm}$ a $0,36 \mathrm{~mm}$, e na largura de $0,16 \mathrm{~mm}$ a $0,28 \mathrm{~mm}$. A relaçāo larguracomprimento, mostra uma variaçāo de 0,62 a 0,79 .

As câmaras arredondadas, um tanto projetantes, dotadas de paredes lisas, nāo ornamentadas, o tipo da abertura e sua disposiçāo diretamente sôbre a última câmara sem se projetar em um pescoço e as proporções gerais da testa, sāo caracteristicas que permitem reunir esta fórma ao grupo de espécies exemplificado pela espécie Q. seminula (Linné). Nāo foi possível verificar se o dente como na espécie acima é bifurcado na extremidade.

A presente espécie inclue-se em uma das duas secções do gênero Quinqueloculina estabelecidas por Deshayes (em Ellis e Messina, Catalogue of Foraminifera, Quinqueloculina D'Orbigny emend. Deshayes, 1832), a qual é caracterisada por espécies arredondadâs, às vezes subglobulosas, com abertura nāo prolongada. É a fórma de foraminifero mais encontradiça em Ponta de Pirabas.

Col. II/56 D.G.P.

\author{
Quinqueloculina sp. b
}

Est. I, fig. 4-6.

É possivel que os individuos aquí considerados representem uma variaçāo da fórma atrás referida. Foram separados dessa última por serem bem mais largos, nāo só considerando-se a testa em 
necida por Cushmann e Cahill (2, Est. 3, figs. 4 a-c) que reconheceram a espécie na formaçāo Choctawhatchee, Mioceno da Flórida. Contudo é duvidoso nos espécimes aquí considerados o caráter do dente, além disso, os mesmos possuem dimensões maiores que as indicadas por Cushman e Cahill (Idem p. 11).

Col. II/59-60 D.G.P.

\author{
Pyrgo sp. b \\ Est. I... fig. 4; Est. IIJ, fig. 1-2.
}

Testa alongaúa. Câmara e periferia arredondada. Suturas distintas, deprimidas. Parede lisa, polida, de côr branca de porcelana; abertura pequena, dotada de um dente grande, bifurcado.

Dimensões: comprimento $0,45 \mathrm{~mm}$; largura $0.33 \mathrm{~mm}$; espessura $0,24 \mathrm{~mm}$.

Col. II/61 D.G.P.

\title{
Familia Peneroplidae
}

Peneroplis sp.

Est. II, fig. 5-6; Est. III, fig. 7 .

Testa grande, alongada, planospiral, comprimida, mais espêssa no centro, adelgaçando-se para uma das extremidades, evoluta. Poucas câmaras (9), largas, dotadas de secçāo quadrangular, salientes, partindo tôdas de um mesmo ponto, e curvando-se para o lado oposto ao sentido de seu crescimento inicial e aumentando gradativamente de tamanho, de maneira que grande parte da periferia é constituida pela última câmara. A parede é calcária e ao que parece imperfurada. Umbilico inexistente. A abertura consiste em uma série dupla de poros implantados na face que fórma a periferia da última câmara.

A parede calcária imperfurada, o tipo de enrolamento planospiral, a abertura consistindo de uma série de poros na face da última câmara que fórma a periferia e o arranjo das cãmaras são caractéres das Peneroplidae.

As câmaras simples, nāo divididas em câmarazinhas secundárias, é caracteristico do gênero Peneroplis. Êste se estende do Eoceno até hoje.

Dimensões: diâmetros $0,70 \mathrm{~mm}$ e $0,43 \mathrm{~mm}$; espessura $0,22 \mathrm{~mm}$. Esta espécie parece ser rara na fauna da Ponla de Pirabas.

Col. II/62 D.G.P

\section{Familia Rotalidae}

Discorbis? sp.

E.st. 1, fig. 11-13.

Testa trocospiralada, deprimida, evoluta, no lado dorsal, involuta no lado ventral. Parede calcária perfurada. Càmaras pro- 
jetando-se um pouco para fóra, com suturas deprimidas produzindo uma periferia discretamente lobada. As câmaras aumentam rápidamente de tamanho. Sete câmaras sāo visiveis no lado ventral, dez no lado dorsal. A testa é constituida de pouco mais de uma volta. Umbílico visivel. A última câmara projeta-se um pouco sôbre o umbilico.

A abertura é uma estreita fenda na base da face apertural, seus limites sendo no entanto imprecisos.

Dimensões: diâmetros $0,18 \mathrm{~mm}$ e $0,11 \mathrm{~mm}$; espessura $0,075 \mathrm{~mm}$. Esta espécie parece ser rara na fauna de Ponta de Pirabas.

Col. II/63 D.G.P

\author{
"Rotalia" sp. \\ Est. III, fig. 5-6.
}

Testa cônica, plano-convexa. Lado ventral convexo, lado dorsal plano. Parede calcária perfurada. As câmaras nc̄o se projetam; portanto a periferia é lisa, nāo lobada. Umbílico do lado ventral fechado por uma rolha ("plug") As últimas câmaras dêste lado, se projetam ligeiramente para a regiāo umbilical. O lado ventral mostra oito câmaras que aumentam gradativamente de tamanho. No lado dorsal, tôdas as câmaras, em número de doze sāo visiveis. A testa é formada por uma volta e meia. Suturas limbadas, alargando-se para o umbílico grande do lado ventral. Suturas estreitas e curvas no lado dorsal. A abertura é estreita e constituida por uma fenda deslocada para o lado ventral, próxima à periferia e no fundo de uma depressāo da última câmara.

Dimensões: diâmetros $0.15 \mathrm{~mm}$ e $0.13 \mathrm{~mm}$; espessura $0.09 \mathrm{~mm}$.

A presença de uma rolha cobrindo o umbílico no lado ventral, permite a referência da espécie ao gênero "Rotalia" Êste gênero é colocado aquí entre aspas devido ao fato de que recentemente êle foi muito subdividido, o valor destas subdivisões em muitos casos sujeitos a críticas.

A espécie parece ser rara na fauna de Ponta de Pirabas.

Gyroidina? sp.

Est. IV. fig. 7-8.

Testa pequena, trocospiralada, muito deprimida, quasi planospiral, evoluta no lado dorsal, involuta no lado ventral. A abertura é constituida por uma estreita fenda na base da face da abertura deslocada para o lado ventral. Umbílico bem desenvolvido, profundo e estreito. Parede calcária perfurada. Periferia ligeiramente angular. Septo curvando-se para o lado da abertura até o meio do lado ventral, dirigindo-se entāo para o lado oposto até a periferia, formando um ângulo bem aberto; a partir da periferia, no lado dorsal, curva-se para o lado da abertura até o meio, quando inflete novamente para o lado oposto em um ângulo bem aberto. 
As câmaras nāo se projetam para fóra, portanto a periferia nāo é lobada, e aumentam gradualmente de tamanho. Onze câmaras formam uma volta. A testa é constituida de pouco mais de uma volta.

Dimensões: diâmetros $0,20 \mathrm{~mm} \mathrm{e} 0,18 \mathrm{~mm}$; espessura $0,075 \mathrm{~mm}$.

\section{Eponides sp.}

Est. III, fig. 3-4.

Testa trocospiralada, mais ou menos circular, biconvexa, relativamente grande, lado dorsal francamente convexo, lado ventral ligeiramente convexo. Parede calcária perfurada. As câmaras nāo se projetam; portanto a volta do corpo é lisa, nāo lobada. Tôdas as câmaras visíveis do lado dorsal, só a última volta do corpo visivel do lado ventral. Nove câmaras formam uma volta do corpo. Duas voltas e pouco formam o indivíduo. Umbilico ventral pequeno, fechado por material conchifero hialino. Suturas limbadas, curvas, dispostas obliquamente, afastando-se da abertura à medida que se dirige para a periferia. Sutura espiral grossa. Periferia angular. A abertura é uma estreita fenda ao longo da base da última câmara, no lado ventral.

A testa trocospiralada, biconvexa, com abertura ventral e cavidade umbilical preenchida por material conchífero hialino, é característica do gênero Eponides.

Dimensões: diâmetro $0,33 \mathrm{~mm}$; espessura $0,16 \mathrm{~mm}$.

A espécie parece ser rara na fauna de Ponta de Firabas.

Col. II/64 D.G.F.

\section{Familia Nonionidae \\ Nonion sp. a \\ Est. IV. fig. 4-6.}

Testa pequena, bilateralmente simétrica, planospiral, parcialmente evoluta, mais longa que larga. Parede calcária perfurada, lisa, excepto na regiāo umbilical, onde aparece material conchifero secundário, granuloso, secretado pelo animal. Câmaras projetando-se para fóra, com suturas deprimidas produzindo uma periferia discretamente lobada. Esta periferia é subangulosa. As câmaras aumentam gradativamente de tamanho. Umbílico grande deprimido. Suturas limbadas, deprimidas, ligeiramente curvas, alargando-se para a regiāo umbilical. Ambos os lados da testa mostram onze câmaras as quais formam uma volta inteira, enquanto as partes mais antigas da testa sāo formdas por duas ou três câmaras pouco visiveis. A abertura consiste em uma estreita fenda na base da última câmara.

Dimensões: diâmetros $0,22 \mathrm{~mm}$ e $0,18 \mathrm{~mm}$; espessura $0,075 \mathrm{~mm}$.

A presente espécie coloca-se tipicamente no gênero Nonion pela sua abertura, pelo seu enrolamento planospiral, pelo seu tra- 
çado mais longo que largo e pelo número de câmaras formadoras de uma volta ao corpo, relativamente numerosas. O gênero se esiende do Jurássico até hoje. Contudo só se torna comum a partir do Eoceno.

Pelo seu umbilico deprimido e preenchido por material conchífero granuloso, associa-se a diversos outros representantes do mesmo gênero, representantes êstes que começam a aparecer, ao que parece, no Eoceno. O referido umbilico largo e deprimido, preenchido por meterial conchifero granuloso associado com as suturas limbadas curvas que se alargam para o umbilico, produzindo um esboço estrelado da regiāo umbilical, lembra entre outras, a espécie N. dingdeni Cushmann, do Mioceno da Alemanha (V Ellis e Messina, Catalogue of Foraminifera) Contudo distingue-se da mesma pelo fato das câmaras aumentarem gradativamente de tamanho, pela periferia meros angulosa e principalmente pelo caráter parcialmente evoluto do seu enrolamento. Nêste particular apioxima-se de $N$. schencki Kleinpell do folhelho de Monterrey do Mioceno Superior da Califórnia. Entretanto, distingue-se desta, entue outros caracteres, pelo aumento gradativo das câmaras e pelo umbilico muito mais largo e ornamentado.

A espécie parece ser rera na fauna de Ponta de Pirabas.

Col. II $/ 65$ D.G.P

\section{Nonion sp. $b$}

Est. IV. Fig. 1-3.

Testa planospiral, lenticular, involuta em ambos os lados, biiateralmente simétrica. Farede calcária perfurada. Câmaras arredendadas, as últimas projetando-se ligeiramente para fóra. As primciras câmaras, entretanto, nāo se projetam. Suturas pouco distintas. As câmaras aumentam gradativamente de tamanho. Umbi!ico muito pequeno.

Dimensões: diâmetros $0.31 \mathrm{~mm}$ e $0,28 \mathrm{~mm}$; espessura $0,12 \mathrm{~mm}$.

Embora o caráter da abertura nāo seja claro, esta espécie pelos outros caractéres parece pertencer ao gênero Nonion. No seu aspecto geral e proporções aproxima-se de $N$ goudkoffi Kleinpell do Mioceno Superior da Califórnia, Estados Unidos. Somente que os indivíduos aquí estudados contrastam-se com os da Califórnia por serem menores, possuirem as suturas um tanto indistintas e câmaras meros projetantes. Tanto os indivíduos do Mioceno da Califórnia como os aquí estudados, possuem o caráter involuto de ambos os lados, nove câmaras formando a última volta, umbílico pequeno, câmaras aumentando gradualmente, periferia larga e arredondada, e a relaç⿳亠丷o entre as dimensões. Firabas.

Esta espécie é relativamente comum na fauna de Ponta de Col. II/66 D.G.P. 


\section{CONCLUSÕES}

A associação aqui estudada apresenta as seguintes particularidades que sāo caracteristicas de associações mais recentes que o Cretáceo:

1) Abundância de Quinqueloculina. Apesar dêste gênero ter aparecido no Jurássico, só se torna comum a partir do Eoceno (Glaesner, 5, p. 117).

2) O gênero Peneroplis se estende do Eoceno até hoje. (Cushman 1, p. 222).

3) As espécies de Nonion aquí referidas possuem particularidades da testa que lembram espécies que se distribuem do Eoceno até hoje.

Embora algumas das fórmas descritas apresentem semelhanças com espécies do Mioceno norte-americano, nāo se tentou correlasāo mais estreita em virtude do pouco material à disposiçāo.

\section{BIBLIOGRAFIA}

1 Cushman, J. A. (1940) - Foraminifera - Their classification and economic use. 3. ediçāio, Harvard Univ. Press.

2. Idem e Cahill, E. P (1933) - Miocene Foraminifera of the Coastal Plain of the eastern United States. United States Geol. Surv., Prof. Paper 175 A.

3. Derby, O. (1894) - The Amazon Upper Carboniferous fauna. J. Geol. 2, p. 480-501.

4. Ellis, B. F e Messina, A. R. - Catalogue of Foraminifera. Am. Mus, of Nat. Hist, Special Publication.

5. Glaessner, M. F. (1944) - Principles of Micropaleontology, Melbourne Univ. Press.

6. Katzer, F (1933) - Geologia do Estado do Pará. (Traduçāo anotada) Bol. Mus. Paraense E. Goeldi, vol. 11, Belém.

7 Liais, E. (1872) - Climats, Géologie, Faune et Géographie Botanique du Brésil. Garnier Frères, Libraires Éditeurs Paris.

8. Maury, C. J. (1925) - Fósseis terciários do Pará. Serv. Geol. Min. Monografia n. 4, Rio de Janeiro.

9 Maury, C. J. (1936) - O Cretáceo de Sergipe, Serv. Geol. Min., Monografia n." 11, Rio de Janeiro.

10. Oliveira, A. I. e Leonardos, O. H. (1943) - Geologia do Brasil, 2: Ediçāo, Serviço de Informaçāo Agrícola, Rio de Janeiro. 
11 Paiva, G. (1939) - Serv. Geol. Min., Relatório Anual do Diretor para 1938, p. 57 Rio de Janeiro.

12. White, M. P (1929) - Index Foraminifera of the Tampico Embayment, J. Paleont., vol. 2, n. 1, p. 55.

13. Zeller, E. J. (1950) - Stratigraphic Significance of Mississippian Endothyroid Foraminifera, Univ. of. Kansas, Paleont. Contributions - Protozoa, Art. 4.

\section{HXPLICACTO DAS WSTAMPAS}

IESTMPA I

Quinqueloculina sp. a - Figs. 1 e 2 - Vistas laterais. Fig. 3 - Vista apertural. $\times 136$.

Q. sp. b-Figs. 4 e 5 - Vistas laterais. Figr. 6 - Vistá apertural. $\mathrm{X}$ 68.

Q. Sp. c - Figs. 7 e 8 - Vistas laterajs. Fig. 9 - Vista apertural. X 68. Pyrgo s!l. a - Fig. 10 - Secç̃o transversal. $X$ (is.

Dincorbis sp. - Fig. 11 - Vista dorsal. Fig. 12-Vista ventral. Irig. 13- Vista periferal. $\times 136$.

\section{ESTAMPA II}

Pyro sp. a -- rig. 1 - Vista apertural. Fig. 2 - Vista frontal. Fig. 3 - Vista lateral. $\mathrm{X} 68$.

P sp. b- Fig. 4 -- Vista lateral. X 136.

Peneroplis sp. - Figs. F e 6 - Vistas laterais. $\mathrm{X} 68$.

\section{WSTAMIPA III}

Pyrgo sp. b- Fig. 1 - Vista frontal. Fig. 2 - Vista apertural. X 136.

Eponides sp. - Fjg. : - Vista dorsal. Fig. 4 - Vista ventral. X 136.

“Rotalia" sp. - Fig. 5 - Vista dorsal. Fig. 6 -- Vista ventral. $x 136$.

Peneroplis sp. - Fig. 7 - Vista periferal, X 68 .

ESTAMFA IT

Nonion sp. b-Figs. 1 e 2 - Vistas laterais. Fig. 3 - Vista periferal. X 136. x. s!). : Figs. 4 e j- Vistas laterais. Fig. 6 - Vista periferal. X 136. Gyroidina: sp. - Fig. $\tau$ - Vista dorsal. Fig. 8 - Vista ventral. X 136. 

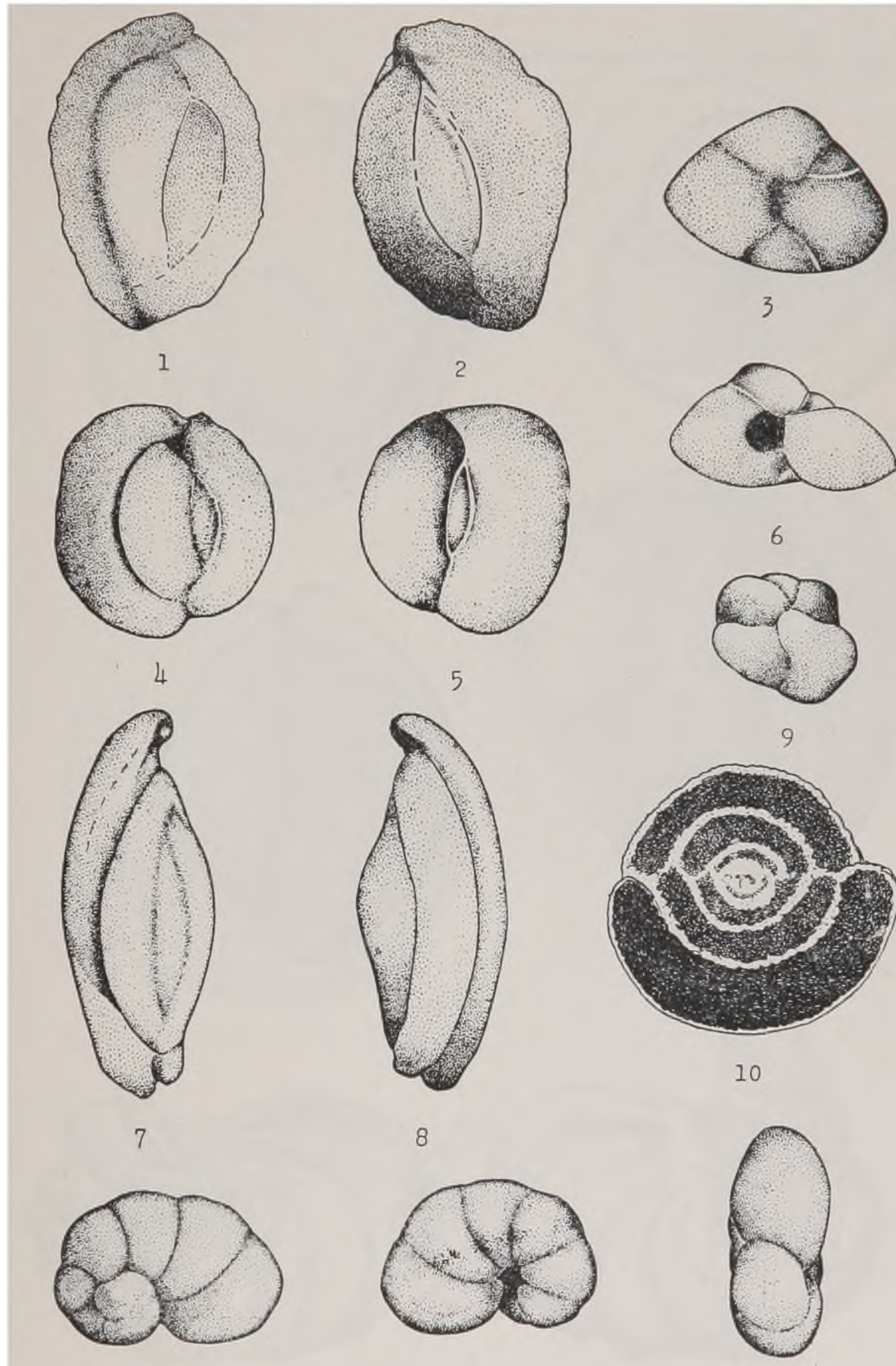
Petri, Ocorrências de foraminiferos etc.
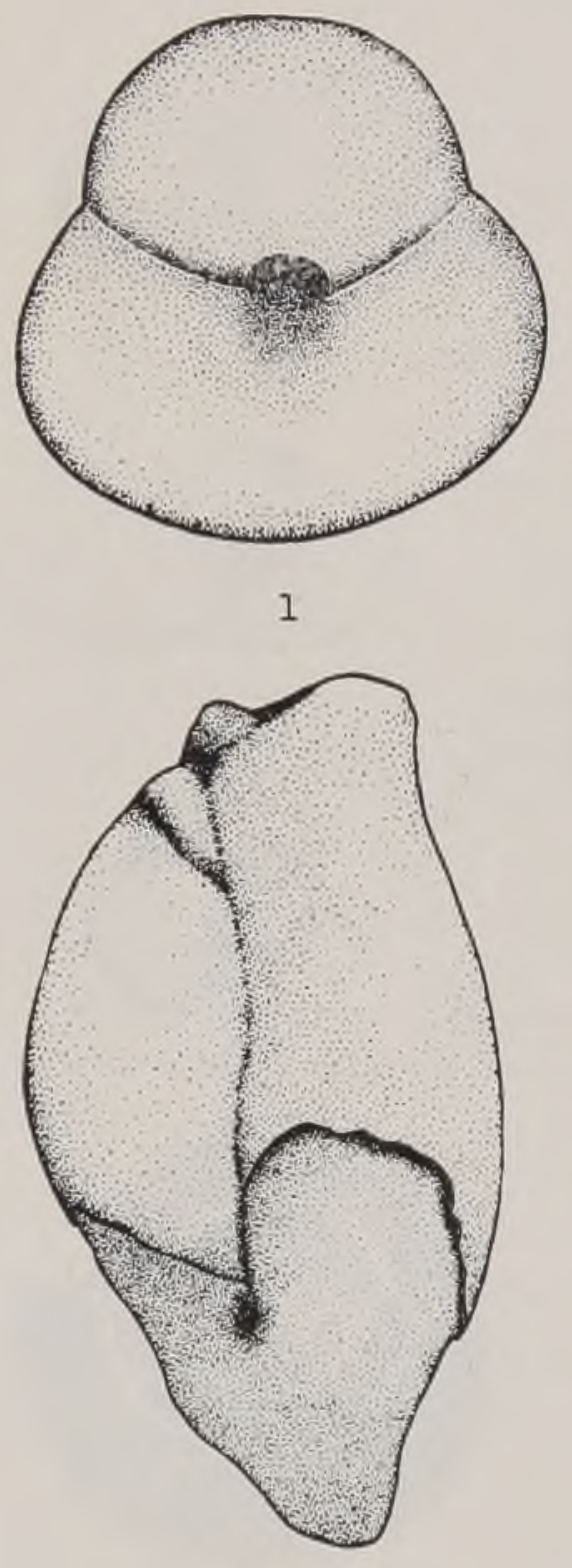

4

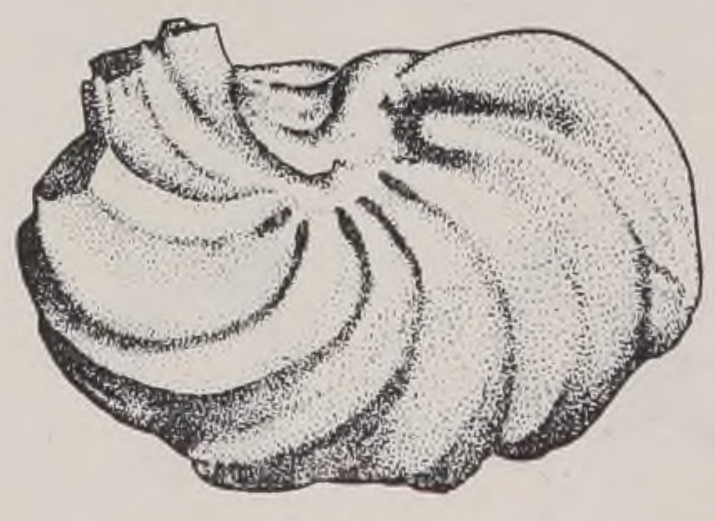

5
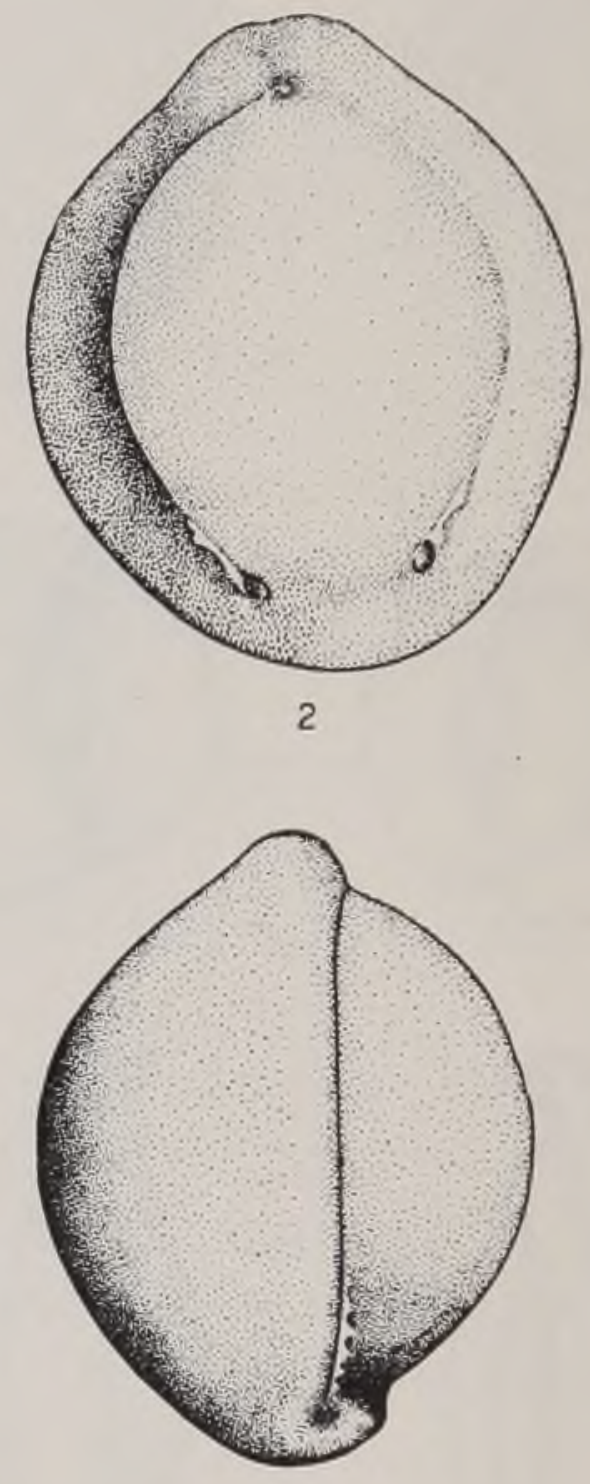

3

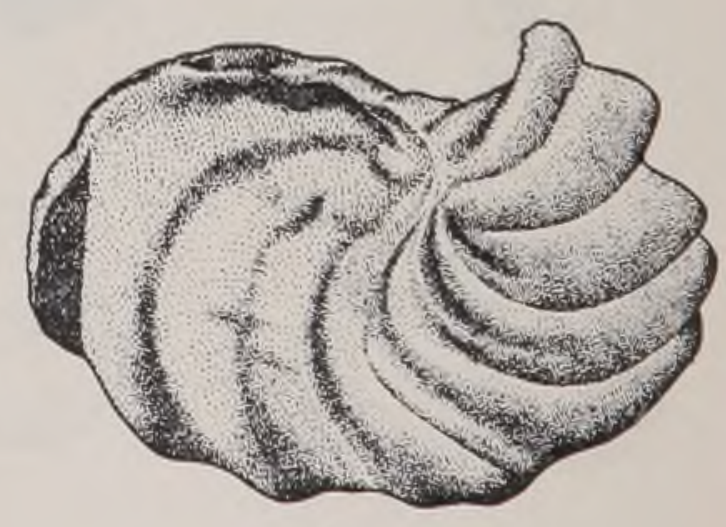

6

Des. A. Monte 
Petri, Ocorrêneias de foraminiferos etc,
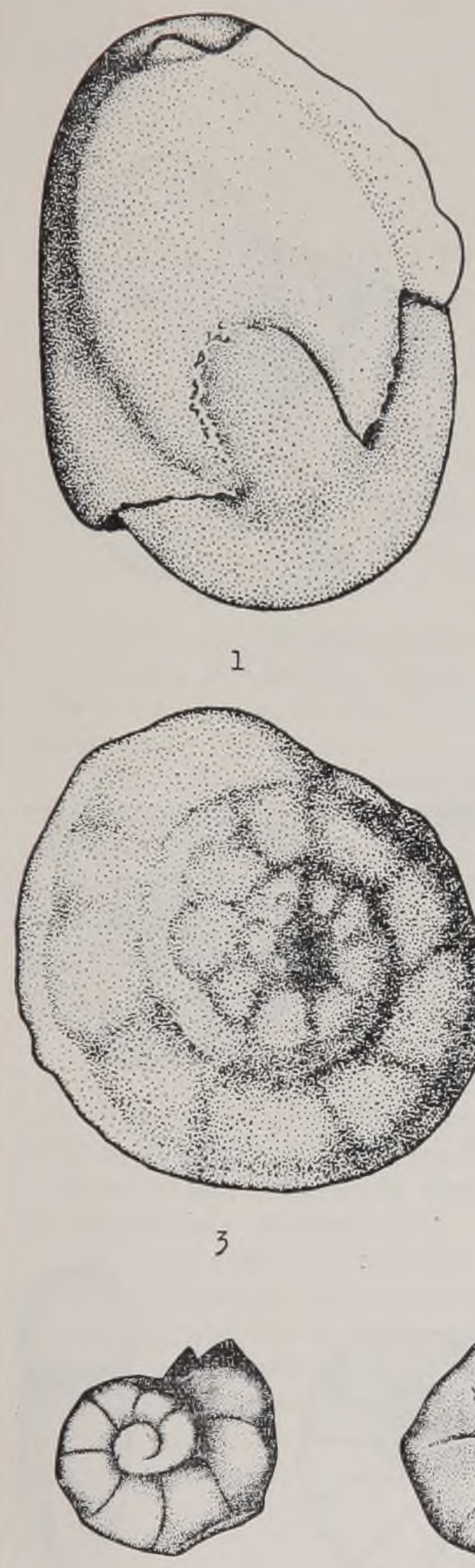

5
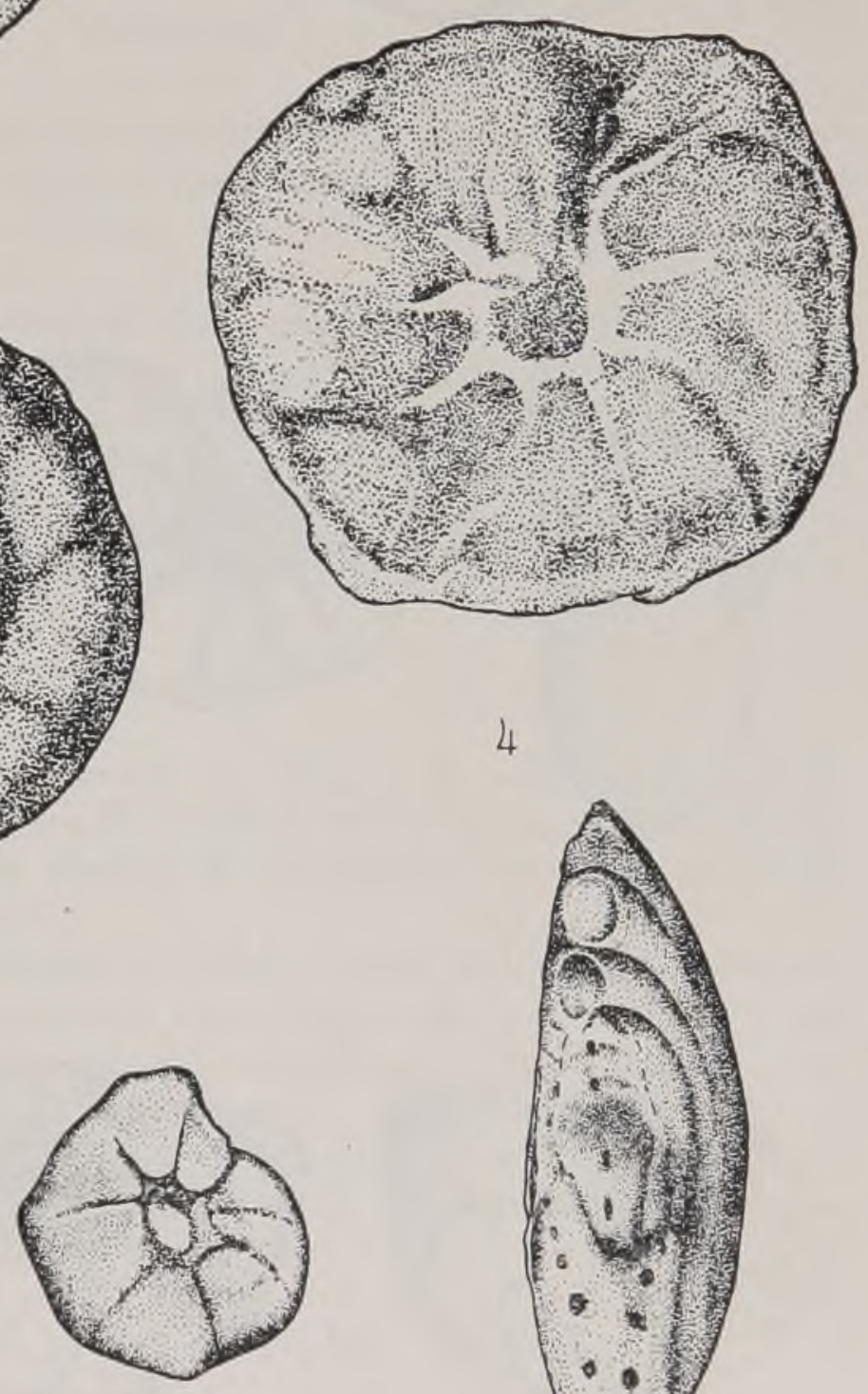

4

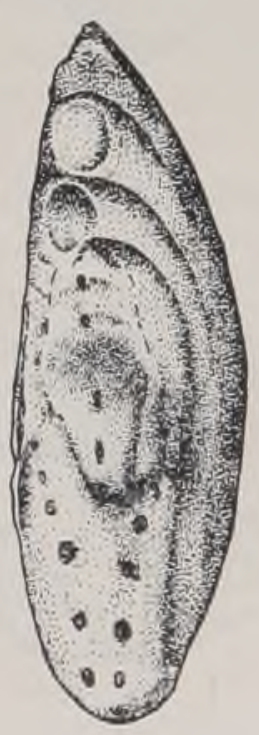

Des, A. Monte 
Petri, Ocorrências de foraminiferos etc.

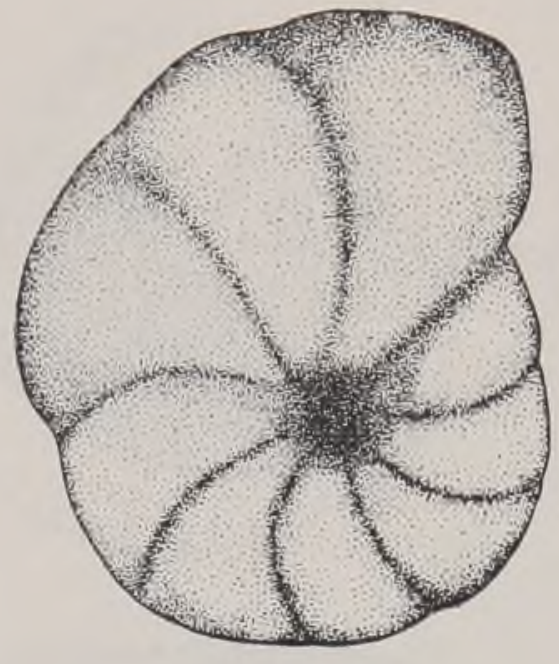

1

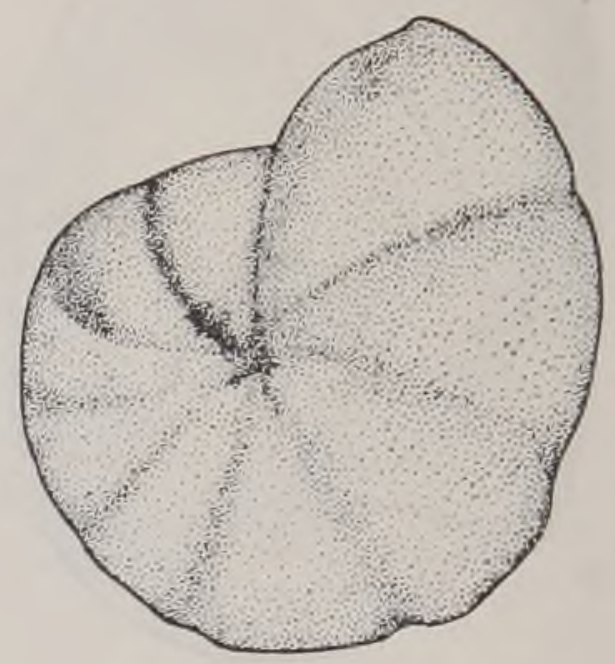

2
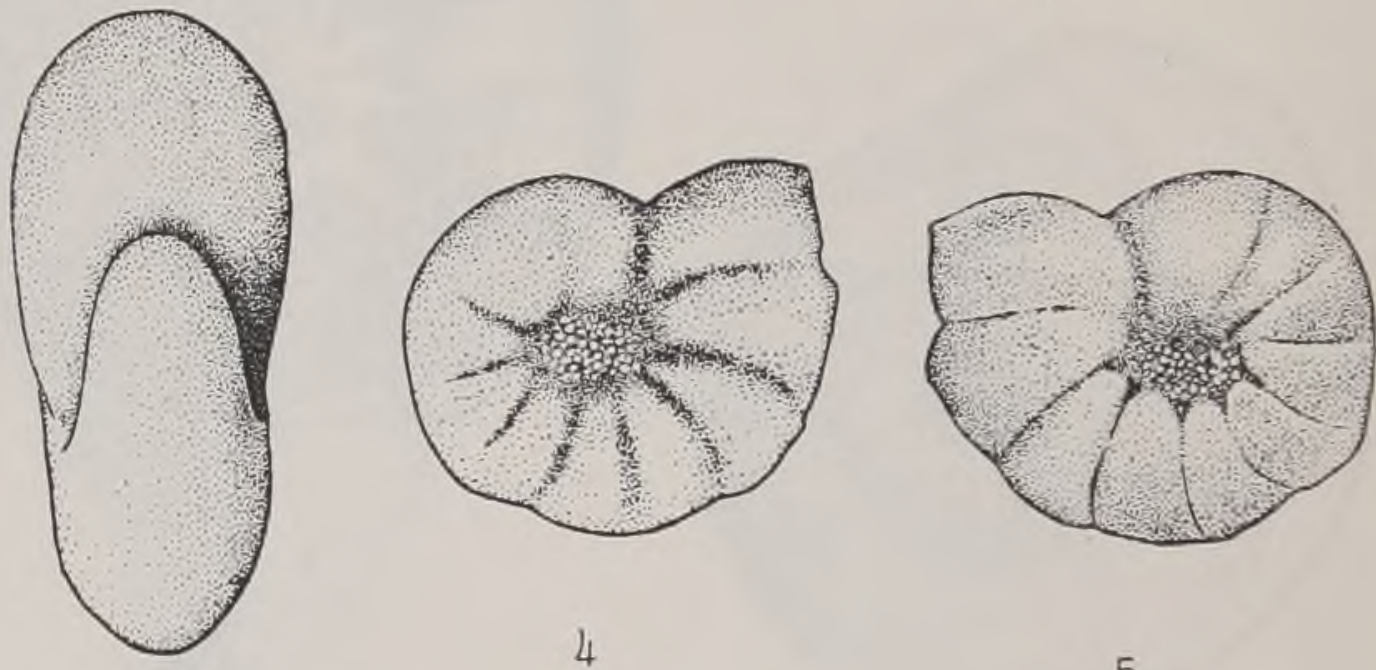

3

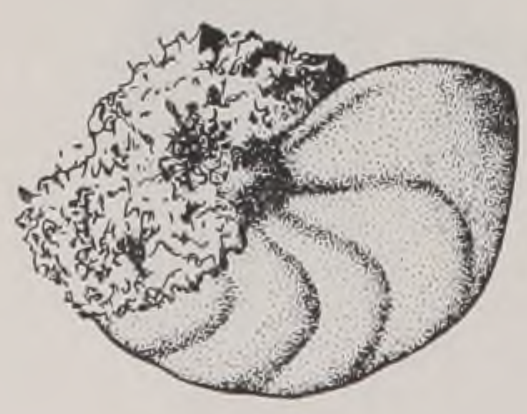

8

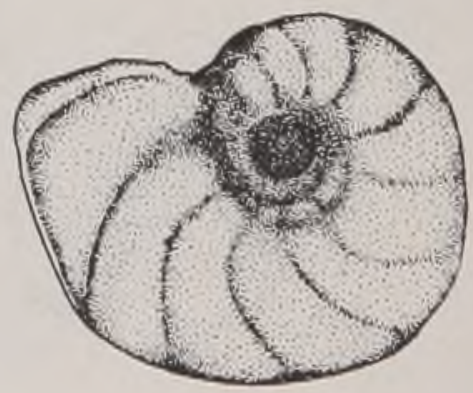

7

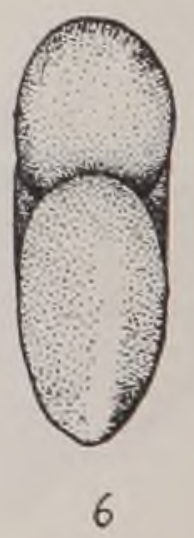

Des, A. Monte 